\title{
A unified treatment of the exceptions to the Agent/ECM Correlation
}

\author{
Yuki Ito*
}

LSA Annual Meeting, Portland, January 8-11, 2015

1. Introduction. Based on the contrast between the believe-class and the wager-class verbs, Pesetsky (1992) makes a generalization that agentive verbs do not allow ECM (the Agent/ECM Correlation).

(1) Mary $\left\{\right.$ believed/considered $/ *^{*}$ wagered $/ *^{*}$ said $/ *^{*}$ claimed $/ *^{*}$ yelled $\}$ Bill to have read the book.

However, he notes two classes of exceptions to the generalization. The first is the declare-class:

(2) a. Congress declared March to be National Syntax Month.

b. The king decreed March 1992 to have 32 days.

c. The judge ruled Bill to be competent to stand trial. (Pesetsky 1992:21)

The second is the show-class (show, demonstrate, prove, reveal):

(3) Sue deftly showed the Greenhouse Effect to be even more pernicious than previously thought. (Pesetsky 1992:20)

I argue that the two classes of exceptions can be uniformly treated as causatives and that the Agent/ECM Correlation can be seen as an instance of the broader 1-syntax finding that "not all internal arguments are created equal"-with agentive activity verbs the root selects an internal argument, but not with change-of-state verbs (Basilico 1998, Hale and Keyser 2002, Alexiadou and Schäfer 2011, Cuervo 2014).

2. The declare-class as resultatives. As Pesetsky observes, the narrow scope possibility establishes that the declare-class is indeed a case of ECM:

(4) a. The Oyster Council declared no month to be an Oyster Month that does not have an $r$ in it.

b. The judge ruled only Sue to have cause for action. (Pesetsky 1992:21)

He suggests that these cases involve double $\theta$-marking of the infinitival subject, and extends the analysis to estimate (Postal 1974):

(5) a. Sue estimated Bill's weight to be $150 \mathrm{lbs}$.

b. * Sue estimated Bill to weigh $150 \mathrm{lbs}$.

(6) a. Sue estimated Bill's weight.

b. * Sue estimated Bill.

By formulating the Agent/ECM Correlation as in (7), this class of exceptions is taken care of.

\footnotetext{
*Author: Yuki Ito, University of Maryland (yito@umd.edu)
} 
(7) Agent/ECM Correlation (Pesetsky's version 1 of 2):

If $\alpha$ assigns the $\theta$-role Agent, $\alpha$ Case-marks $\beta$ only if $\alpha \theta$-marks $\beta$

I propose that the impression of double $\theta$-marking is an illusion, stemming from the fact that these sentences are instances of resultatives like John hammered the metal flat. The resultatives literature has argued that the thematic relation of the object to the means-describing verb is not part of the semantics of resultatives (Kayne 1985, Hoekstra 1988, McIntyre 2004, Kratzer 2005, Williams 2008). This is based on the observation that sentences like (8) trigger an implication that the object of hitting is the metal:

(8) A little more hammering should get the metal flat. (Kayne 1985:122)

This invites the possibility that the same extrasemantic inference is responsible for the apparent thematic relation found in resultatives. The strong evidence comes from the phenomenon of nonsubcategorized objects with obligatorily transitive verbs (McIntyre 2004):

(9) a. I tore the buttons off the shirt.

b. I locked him in the cellar.

This phenomenon establishes that in resulatives the means-describing verb does not enforce selection, suggesting that in resultatives like John hammered the metal flat too, the object is not selected by the verb. Thus, by analyzing the declare-class verbs as resultatives, the apparent double $\theta$-marking can be explained in the same way.

Support for the resultative analysis comes from nominalization. Since Chomsky (1970), ECM is known to disallow nominalization (*John's belief/believing of Mary to have left) while resultatives allow nominalization:

(10) a. The watering of tulips flat is a criminal offence in Holland. (Carrier and Randall

b. Kim's hammering of the metal flat (Borer 2013:108)

1992:201)

We observe that the declare-class verbs allow nominalization:

(11) a. Congress' declaration of March to be National Syntax Month

b. ? The king's decree of March 1992 to have 32 days

c. ?The judge's ruling of Bill to be competent to stand trial

What is crucial at this point is that the second class of exceptions to the Agent/ECM Correlation-the show-class-is lexically causative verbs. Their lexically causative status is indicated by (i) the fact that they allow causer subjects:

(12) \{Sue deftly/The horrible weather last summer\} showed the Greenhouse Effect to be even more pernicious than previously thought.

(Pesetsky 1992:20-21)

and (ii) the fact that they create subject (as opposed to object) nominalization as result nominals: 
(13) a. The court's declaration that Bill was dead

$=$ The court's declaration was that Bill was dead

b. Sue's estimation that Bill's weight was $150 \mathrm{lbs}$

$=$ Sue's estimation was that Bill's weight was $150 \mathrm{lbs}$

c. Holmes' proof that Moriarty was the murderer

$\neq$ Holmes' proof was that Moriarty was the murderer

The peculiarity of these verbs is the involvement of sublexical modality in the sense of Koenig \& Davis (2001):

(14) "Holmes caused Moriarty to be the murderer in all worlds compatible with his proof"

See Martin and Schäfer (2013) for an analysis of defeasible causatives such as offer and teach along the same line.

Now, because resultatives are causative sentences built on verbs that are not lexically causative, the existence of these lexically causative verbs supports the resultative analysis proposed here. As Beavers (2012) points out, the idea pursued in the study of resulatives is that "resultatives represent event structures already found in lexical causatives."

3. Explaining the ECM possibility. Contrary to the standard claim, Ito (2014) shows that the ECM subject of the wager-class verbs behaves in parallel with that of the believe-class and therefore can receive Case without $\mathrm{A}^{\prime}$-movement. He ascribes the contrast between the two classes to Richards' (2010) distinctness condition, which prohibits a linearization statement $*<\alpha, \alpha>$. Specifically, he proposes that the wager-class verbs select an infinitival complement with a Case-related projection FP, unlike the believe-class, which selects TP. On the assumption that $\mathrm{F}(\mathrm{P})$ and $\mathrm{D}(\mathrm{P})$ count as nondistinct, the configuration gives rise to a distinctness violation (with distinctness violations avoided only when the ECM subject is displaced outside of $\operatorname{Agr}_{0} \mathrm{P}$ ):

$$
\text { [vP Mary v [AgroP Agro [vp wager [Fе F } \mathrm{F}^{0} \text { [те Bill to have read the book]]]]] }
$$

Postulation of FP is motivated by the fact that for nominal complements the wager-class verbs exhibit a selectional property that is different from the believe-class (Moulton 2009):

(16) a. $\quad\{$ Pinchwife does not believe/*Fred said $\}$ the rumor that Horner is impotent.

b. $\quad\{$ Consider $/ *$ We never thought $\}$ the idea that vitamin supplements in pregnancy lead to healthy babies.

c. $\quad\{$ Rita held the/*?He yelled his $\}$ belief that Jesus will return again.

While agentive verbs have this FP-selection requirement, in resultatives, the means-describing verb does not enforce selection, as we have seen. Thus, in the declare-class cases, no distinctness violation arises by virtue of FP not being selected.

At this point, it is worthwhile to cast the current analysis in the 1-syntax framework (Hale and Keyser 1993), which has obtained the result that "not all internal arguments are created equal" (Basilico 1998, Hale and Keyser 2002, Alexiadou and Schäfer 2011, Cuervo 2014). Levin (1999) observes that the agentive activity verbs and change-of-state verbs behave differently 
with respect to their internal arguments. The internal arguments of agentive activity verbs are (i) variable in theta-roles (eat a cake/climb a mountain/cut a rope), (ii) variable in syntactic category (cut/cut at), and (iii) non-obligatory (eat, write, drive), in contrast with the internal arguments of change-of-state verbs (break, open) which are uniformly interpreted as patient. The 1-syntax interpretation of this contrast is that agentive activity verbs select an internal argument while change-of-state verbs do not (Cuervo 2014). Though the precise implementation differs between researchers, the consensual idea is that change-of-state verbs involve a more complex event structure as a result of which the internal argument is base-generated as an inner subject.

With this background, it is crucial to observe that the wager-class verbs pass the test of agentive, activity verbs. Since Hale and Keyser (1993), agentive, activity verbs are commonly derived via incorporation of the root into $\mathrm{V}_{\mathrm{DO}}$. Because of this derivation, agentive, activity verbs typically exhibit cognate objects (e.g. dance a dance). The wager-class verbs indeed exhibit cognate objects (Moulton 2009; John thought a thought/He claimed an outrageous claim/She whispered a nasty whisper).

Recall that under the current analysis, the unacceptability of ECM is due to a PF problem (distinctness violation), which arises owing to selection of FP, triggered by the selectional property of agentive ECM verb roots. Thus, the fact that this happens only in the agentive context, where the root selects an internal argument, receives a natural account under the 1-syntax framework reviewed above.

Indeed, the virtue of moving to the 1-syntax framework is that the phenomenon at issue exhibits verbal elasticity, which is the forte of the constructivist (as opposed to lexicalist) approach. Bošković (1997) observes that when show-class verbs are put in a context that forces unambiguously agentive interpretation, ECM becomes degraded (?*For your homework, prove the Case Filter to hold at LF cf. For your homework, prove that the Case Filter holds at LF). Similarly, Pesetsky (1992) notes that when psychological verbs, which typically fall under the believe-class, are used agentively, ECM becomes degraded (Poor Bill. I remember him to have made valuable contributions to his field/??Please don't offend Bill. Remember him to have made valuable contributions to his field cf. Please don't offend Bill. Remember that he has made valuable contributions to his field). These observations indicate that what is crucial for the Agent/ECM Correlation is the context the root appears in, showing the virtue of the constructivist approach.

\section{References}

Cuervo, María Cristina. 2014. Arguments for a root. Theoretical Linguistics 40. 375-387.

Ito, Yuki. 2014. Raising to object in wager/assure-class verbs: A PF account of the defective paradigm. Studia Linguistica. 68. 226-244.

Martin, Fabienne \& Florian Schäfer. 2013. On the argument structure of verbs with bi- and mono-eventive uses. North East Linguistic Society (NELS) 42(1). 297-308.

Moulton, Keir. 2009. Clausal complementation and the wager-class. North East Linguistic Society (NELS) 38(2). $165-178$.

Pesetsky, David. 1992. Zero syntax part 2. http://web.mit.edu/linguistics/people/faculty/pesetsky/infins.pdf (17 March, 2015.) 